\title{
Emissions of reactive nitrogen compounds (RNCs) from two vehicles with turbocharged spark ignition engines over cold start driving cycles
}

\begin{abstract}
This paper reviews the emissions of reactive nitrogen compounds (RNCs) from modern vehicles fitted with spark ignition engines and three-way catalysts. Specific aspects of the pollutants involved - and their formation - are discussed. Cold start driving cycles are scenarios under which emissions of all four RNCs can be significant; the mechanisms behind emissions trends are explored. Experimental data obtained from two vehicles tested over two different cold start driving cycles are presented and analysed. The use of gravimetric and molar metrics are explored. Ammonia, a species which is currently not regulated for passenger cars in any automotive market, is identified as forming the majority of the RNC emissions over the entire driving cycle. While ammonia emissions are strongly linked to aftertreatment system warmup and periods of high load, significant ammonia emissions were also measured under certain hot-running, low load conditions, and even at idle. For the majority of the duration of the test procedures employed, the RNC profile was dominated by ammonia, which accounted for between $69 \%$ and $86 \%$ of measured RNCs in the exhaust gas. Emissions are compared to the available legislative precedents (i.e. emissions limits currently in force in various jurisdictions). Finally, possibilities for control of exhaust emissions of currently unregulated RNCs are briefly discussed.
\end{abstract}

Key words: exhaust emissions, reactive nitrogen compounds, $\mathrm{NO}_{x}$, ammonia, nitrous oxide

\section{Introduction}

The formation of pollutants is an inevitable consequence of combustion, with the relevant parameters being which pollutants are formed and at what levels. Linked to the working cycle, fuel type, etc, spark ignition engines have significant levels of gaseous pollutants in their exhaust gas, a fact which has led to the imposition of emissions limits for the most problematic pollutant types. While a range of measures has been taken to reduce emissions from vehicular powertrains featuring such engines, the single most important solution for emissions control in this context is the three-way catalyst (TWC). This device, use of which was first forced in the 1970s in the USA, remains in near-universal use, including in some SI engines used in sectors other than light duty road transport (passenger cars). Designs and specifications have undergone continuous revision over the past few decades, but the basic concept and functionality remains unchanged. See [14] for a summary of the history of TWCs and a technical overview of their functionalities.

The appellation 'three-way' results from the functionality which consists of oxidation of both hydrocarbons and carbon monoxide, as well as reduction of $\mathrm{NO}_{\mathrm{x}}\left(\mathrm{NO}+\mathrm{NO}_{2}\right)$, which in the case of SI engines consists mostly of NO [3], [14], thus simplifying to:

$$
2 \mathrm{NO} \rightarrow \mathrm{N}_{2}+\mathrm{O}_{2}
$$

Note that reaction (1) is empirical in nature and somewhat idealised; significantly, it does not involve hydrogen (nor water), whereas those species play an active and complex role in TWC functionality. Interactions between $\mathrm{CO}$ and NO are also mentioned in the literature, but such details are beyond the scope of this paper.

Unsurprisingly, the efficacy of reactions to eliminate pollutants (including (1)) is strongly dependent not only on the temperature, but also on the composition of the exhaust gas including the oxygen level. Since exhaust gas results from the interaction between dosed fuel and ambient air, the overall composition changes as the oxygen level changes - as the oxygen level falls, the level of $\mathrm{CO}$ increases.
The ratio between $\mathrm{CO}$ and $\mathrm{H}_{2}$ is normally rather static (at least for a given fuel type), taking an approximate ratio of 3:1. As the aforementioned parameters are strongly controlled by the ratio of air to fuel, that parameter is used to describe the composition of the exhaust gas, most conveniently normalised to stoichiometry for the fuel type (lambda; $\lambda$ ).

Under certain conditions, a TWC can catalytically facilitate reactions which appear to have the same effect as (1) - in such reactions, the concentration of $\mathrm{NO}_{\mathrm{x}}$ is significantly reduced across the TWC, but the final nitrogenous product exiting the TWC is not (entirely) $\mathrm{N}_{2}$. The two main reactions of this type are:

$$
\mathrm{NO}+5 / 2 \mathrm{H}_{2} \rightarrow \mathrm{NH}_{3}+\mathrm{H}_{2} \mathrm{O}
$$

and

$$
2 \mathrm{NO}+\mathrm{H}_{2} \rightarrow \mathrm{N}_{2} \mathrm{O}+\mathrm{H}_{2} \mathrm{O}
$$

With the latter obviously having a lower stoichiometric requirement per mole of NO (i.e. requiring less hydrogen).

In addition to the availability of reagents, temperature exerts a strong influence on the catalytic promotion of reactions occurring in a TWC, particularly in the case of reactions (1)-(3).

\section{Background}

The combustion process generates significant $\mathrm{NO}_{\mathrm{x}}$, which, as mentioned previously, is dominated by NO. Other RNCs are present only at trace levels in the exhaust gas leaving the cylinder [3]. The behaviour and ultimate fate of these NO molecules is complex. For every molecule of NO entering the TWC, there are 6 potential fates:

1. Not engaging in any reaction, exiting the TWC as $\mathrm{NO}_{\mathrm{x}}$ (this definition would include the conversion of $\mathrm{NO}$ to $\mathrm{NO}_{2}$, or vice-versa)

2. Undergoing reaction (1), forming $\mathrm{N}_{2}$

3. Undergoing reaction (2), forming $\mathrm{NH}_{3}$

4. Undergoing reaction (3), forming $\mathrm{N}_{2} \mathrm{O}$

5. Undergoing some other reaction, producing a minor nitrogen-containing product (such as $\mathrm{HNCO}$ ) 
6. Undergoing some other process, involving intermediate steps and species, but which has the same ultimate effect as one of points 1-5 (above)

For the sake of simplicity, points 5 and 6 may be ignored in most contexts. The probability of points $1,2,3$ or 4 occurring varies strongly with TWC operating conditions, especially $\lambda$ and temperature (and therefore with powertrain operating conditions) [3]. The degree to which a given product dominates the output is known as the selectivity. Obviously, the most desirable outcome is for NO to be entirely converted to $\mathrm{N}_{2}$ (process 2; reaction (1)); however, post-TWC exhaust gas contains non-negligible quantities of reactive nitrogen (non- $\mathrm{N}_{2}$ ) [3]. As the engine-out concentration of NO is generally high for SI engines under the majority of operating conditions, especially those without EGR (concentration often on the order of $1-3 \times 10^{3} \mathrm{ppm}$ ), even low selectivity towards a given process/species (e.g. 10\%) can lead to significant post-TWC concentrations of nitrogen in forms other than $\mathrm{N}_{2}$, i.e. reactive nitrogen compounds (RNCs).

Nitrogen is self-evidently not harmful and is not measured in automotive contexts. Of the RNCs $\mathrm{NO}, \mathrm{NO}_{2}, \mathrm{NH}_{3}$ and $\mathrm{N}_{2} \mathrm{O}$, only the first two compounds are regulated in the European Union (together, as $\mathrm{NO}_{\mathrm{x}}$ ). $\mathrm{NH}_{3}$ is regulated for heavy-duty vehicles in the EU and South Korea (using a very simple mean concentration-based limit); $\mathrm{N}_{2} \mathrm{O}$, being a potent greenhouse gas, is regulated in the USA and China, but not in the EU. Growing interest in automotive emissions of $\mathrm{NH}_{3}, \mathrm{~N}_{2} \mathrm{O}$ and even $\mathrm{NO}_{2}$ have led to calls for those compounds to be included as regulated pollutants in the next round of EU emissions legislation, with gravimetric limits likely to apply to both light- and heavy-duty road vehicles, regardless of engine or fuel type.

In this context, simultaneous quantification of emissions of the four RNCs is an important aspect of research into exhaust emissions. Such a measurement can be achieved by two main classes of analyser: a laser-based RNC analyser, or Fourier transform infra-red (FTIR) analysis. As described in [1], BOSMAL's exhaust emissions laboratory no. 2 is equipped with the former, permitting such measurements to be made.

\section{Experimental}

\subsection{Test vehicles and test conditions for laboratory characterisation of RNC emissions}

Two vehicles representing the latest technology for nonhybrid SI powertrains were tested. Details of the vehicles and their powertrains are given in Table 1.

Table 1. Key characteristics of the test vehicles

\begin{tabular}{|c|c|}
\hline Aspect & \begin{tabular}{l|l} 
Vehicle 1 & Vehicle 2 \\
\end{tabular} \\
\hline Vehicle type & Passenger car \\
\hline Engine type & $\begin{array}{l}\text { Turbocharged, direct-injection, } \\
\text { spark-ignition }\end{array}$ \\
\hline $\begin{array}{l}\text { Approx. engine } \\
\text { displacement }\end{array}$ & $1.0-1.5 \mathrm{dm}^{3}$ \\
\hline Number of cylinders & 4 \\
\hline $\begin{array}{l}\text { Approx. vehicle } \\
\text { power:mass ratio }\end{array}$ & $75 \mathrm{~W} / \mathrm{kg}$ \\
\hline $\begin{array}{l}\text { Aftertreatment system } \\
\text { type }\end{array}$ & $\begin{array}{l}\text { Integrated TWC on GPF (so-called 4-way } \\
\text { catalyst), close-coupled mounting position }\end{array}$ \\
\hline Emissions standard & Euro 6d-TEMP \\
\hline $\begin{array}{l}\text { Approx. mileage at } \\
\text { start of testing }\end{array}$ & $60,000 \mathrm{~km}$ \\
\hline
\end{tabular}

The test vehicles both featured the same downsized turbocharged engine. As the engines were identical, it was assumed that the composition of the TWCs were also identical. Vehicle 1's bodywork gave it a slightly higher mass than vehicle 2 (although the difference was only some $5 \%$ ). The power:mass ratio was thus slightly higher for vehicle 2 . Both vehicles met the Euro 6d-TEMP standard, were in sound mechanical condition and showed no OBD errors before (or after) testing. Testing was conducted on the two vehicles at the same nominal mileage stage, corresponding to $37.5 \%$ of the mileage required for demonstration of durability of emissions control systems in EU legislation $(160,000 \mathrm{~km})$. During the aforementioned mileage accumulation, which occurred prior to testing and was not subject to emissions measurements, the usage profiles (driving conditions) of the two vehicles were not identical, but generally similar, consisting of both urban and extra-urban driving occurring under real-world conditions.

The vehicles were tested on a chassis dynamometer in an exhaust emissions laboratory meeting the demands of the latest EU legislation [1, 2]. As mentioned previously, a dedicated, laser-based RNC analyser was used for simultaneous measurement of concentrations of $\mathrm{NO}, \mathrm{NO}_{2}, \mathrm{NH}_{3}$ and $\mathrm{N}_{2} \mathrm{O}$ in the raw (undiluted) exhaust gas. Quantification from raw exhaust gas is essential for $\mathrm{NH}_{3}$ measurements. Gravimetric emissions were calculated based on these concentrations and the flow rate corrected for the instantaneous dilution ratio.

The well-known WLTP and NEDC test procedures were used for testing. In all cases, two tests of each type were performed on each vehicle $(n=2)$, with the mean value obtained taken for further analysis. The WLTP is the legislative procedure (and indeed driving cycle - WLTC) applicable to the test vehicles, while the NEDC is the previous EU legislative cycle. The appropriate road load for the test vehicles was applied, according to the legislative procedures associated with the two cycles. In the case of WLTP testing, the procedure leads to a significantly higher inertia than for the NEDC, as well as increased road load. Commentary on the differences (and similarities) in the two test procedures and the resulting impact on regulated emissions and fuel consumption are available elsewhere $[4,11]$. For the purposes of this paper, it suffices to highlight two similarities:

- both cycles commence from a cold start, with the first acceleration from rest occurring approximately $10 \mathrm{sec}-$ onds after engine start-up,

- the first phase of each cycle consists of urban type driving and the distance covered by the first phase of each cycle is reasonably similar (WLTC Low $=3.1 \mathrm{~km} /$ NEDC UDC $=4 \mathrm{~km}$ );

and to identify three key differences:

- total distance covered $-\mathrm{WLTC}=23.3 \mathrm{~km} / \mathrm{NEDC}=11$ $\mathrm{km}$, i.e. a difference of $212 \%$;

- the distance-specific energy demand for the two cycles, which in the case of the vehicles used in this study was some $25 \%$ higher in the case of the WLTC;

- the NEDC mandates fixed gear usage, according to a one-size-fits-all approach, whereas for the WLTP gear usage must be calculated based on required power at the 
wheel and available engine power, which has the overall effect of generally specifying higher gears for a given level of demanded wheel power, thereby somewhat reducing engine speeds and increasing engine load (compared to the NEDC). The period of cruise at $50 \mathrm{~km} / \mathrm{h}$ in $3^{\text {rd }}$ gear which occurs 4 times during the NEDC is a prime example of this.

Standard, market-available EU petrol was used for testing - the same fuel for both vehicles, for all tests. The fuel was certified to meet the demands of European Norm EN228, was of nominal RON 95, had a nominal ethanol content of $5 \%$ (verified value: $4.9 \%$ ) and a sulphur content of $4.5 \mathrm{mg} / \mathrm{kg}$.

\subsection{Results and discussion}

Regulated exhaust emissions applicable to the vehicle engine type (THC, $\mathrm{NMHC}, \mathrm{CO}, \mathrm{NO}_{\mathrm{x}}$, particulates) were measured according to the EU legislative method. Results are not presented here, but were used to assess test-to-test repeatability. All applicable emissions limits (Euro 6) were met, in all cases. The correlation between the legislative (bag) $\mathrm{NO}_{\mathrm{x}}$ result and the 'virtual $\mathrm{NO}_{\mathrm{x}}$ ' (i.e. $\mathrm{NO}+\mathrm{NO}_{2}$ ) result obtained from the $\mathrm{RNC}$ analyser was generally good and judged to be acceptable for all tests. RNC test results from the two vehicles are presented and discussed below. Results from vehicle 1 during the WLTC are shown in Fig. 1, by the 4 phases that make up the cycle (Low, Medium, High, Extra-High, which occur in that order) and for the entire cycle.

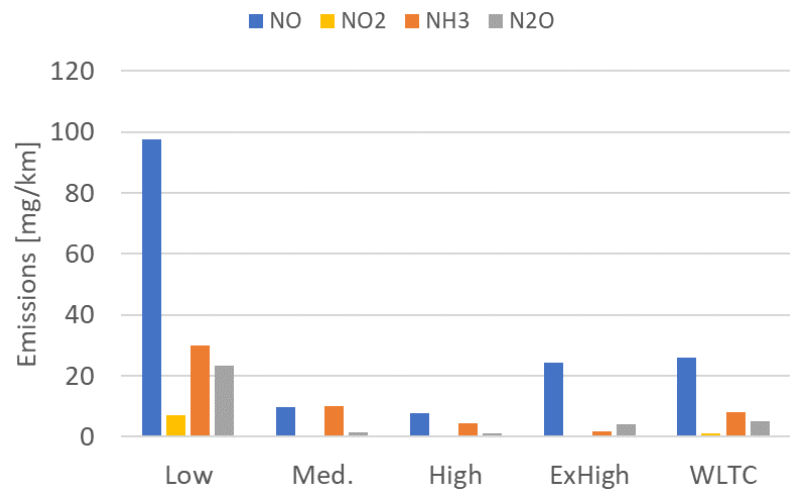

Fig. 1. RNC emissions from vehicle 1 , tested over the WLTC, by phase and for the entire cycle

As is evident from Figure 1, over the entire cycle NO emissions dominate for this vehicle, followed by $\mathrm{NH}_{3}, \mathrm{~N}_{2} \mathrm{O}$ and finally $\mathrm{NO}_{2}$. The mass of $\mathrm{NO}$ emitted is the highest of all RNCs for all phases, except for the 2nd phase (Medium), where emissions of $\mathrm{NO}$ and $\mathrm{NH}_{3}$ are essentially identical. As the range of values is very wide (covering over 2 orders of magnitude), the same data are presented in Fig. 2, on a scale which excludes values $>15 \mathrm{mg} / \mathrm{km}$.

For all four RNCs, emissions were highest during the Low phase. Results from vehicle 1 during the NEDC are shown in Fig. 3, by the two phases that make up the cycle (UDC, EUDC, which occur in that order) and for the entire cycle.

Here emissions were generally numerically lower than over the WLTC. NO dominated during the UDC and $\mathrm{NH}_{3}$ dominated during the EUDC (the only species with emissions $>5 \mathrm{mg} / \mathrm{km}$ ); for results from the entire cycle, NO and $\mathrm{NH}_{3}$ were at essentially identical levels, followed by $\mathrm{N}_{2} \mathrm{O}$ and finally $\mathrm{NO}_{2}$.

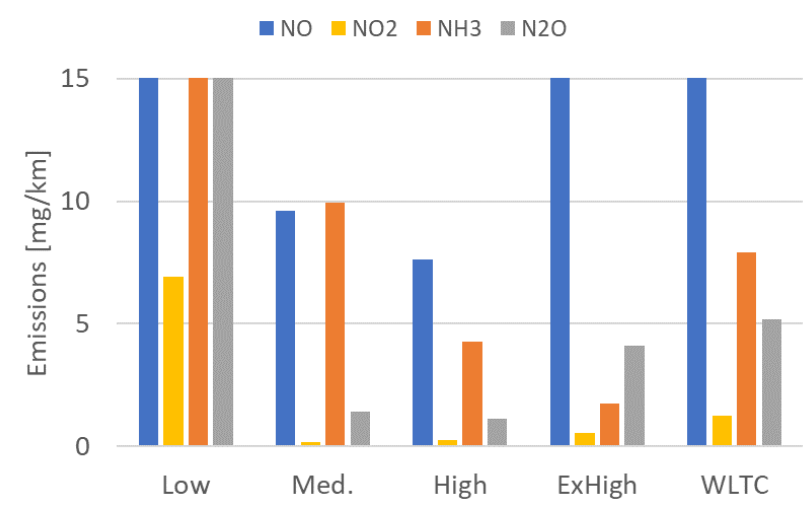

Fig. 2. Lower range of RNC emissions ( $<15 \mathrm{mg} / \mathrm{km})$ from vehicle 1 , tested over the WLTC, by phase and for the entire cycle

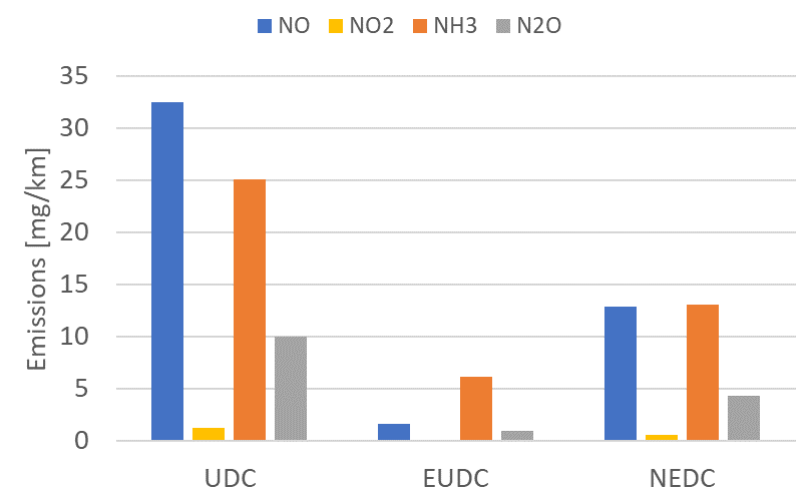

Fig. 3. RNC emissions from vehicle 1, tested over the NEDC, by phase and for the entire cycle

As with results from the WLTC, the initial (cold start, urban speed range) phase was associated with the highest distance-specific emissions, for all four species. Results from vehicle 2 during the WLTC are shown in Fig. 4.

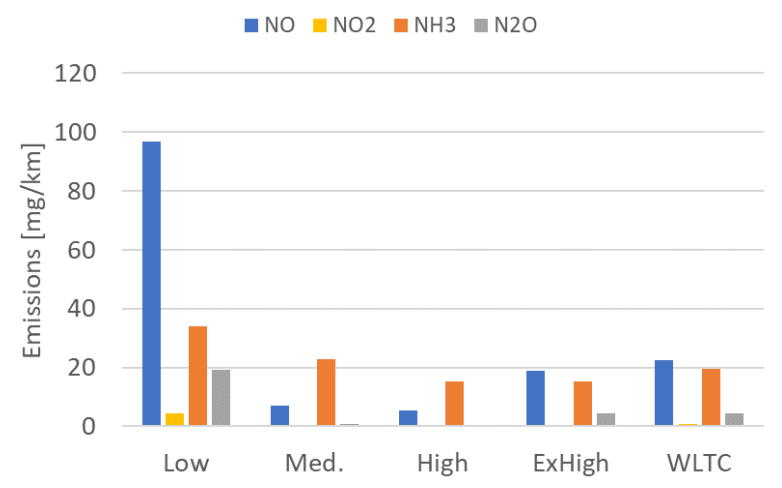

Fig. 4. RNC emissions from vehicle 2, tested over the WLTC, by phase and for the entire cycle

Emissions were similar to those from vehicle 1, with the notable exception that $\mathrm{NH}_{3}$ was at a level much closer to emissions of $\mathrm{NO}$ over the entire cycle, with $\mathrm{NH}_{3}>\mathrm{NO}$ during the 2nd and $3 \mathrm{rd}$ phases. Emissions of all compounds were highest during the 1 st phase. 
Results from vehicle 2 during the NEDC are shown in Fig. 5.

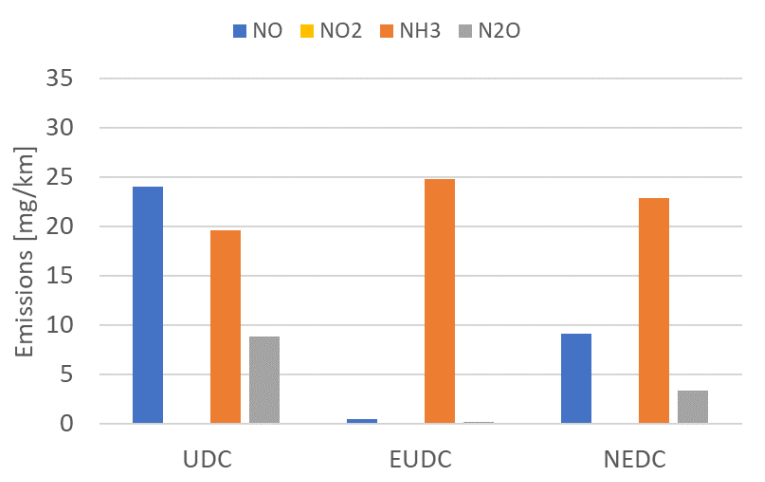

Fig. 5. RNC emissions from vehicle 2, tested over the NEDC, by phase and for the entire cycle

As is immediately apparent from Fig. 5, the behaviour in this case was quantitatively and qualitatively different from the other results (Figs 1-4). Over the entire cycle, emissions of $\mathrm{NH}_{3}$ were highest, being more than twice those of NO. Emissions of $\mathrm{NO}_{2}$ were extremely low (barely detectable) during either phase, with emissions over the entire cycle taking a value $<1 \mathrm{mg} / \mathrm{km}$. During the EUDC phase, emissions of $\mathrm{NO}, \mathrm{NO}_{2}$ and $\mathrm{N}_{2} \mathrm{O}$ were all extremely low, with the RNC profile consisting almost exclusively of $\mathrm{NH}_{3}$; emissions of that compound were at a slightly higher level than during the UDC phase, in strong contrast to results from vehicle 1 and in contrast to results from vehicle 2 obtained over the WLTC (Fig. 4).

The overall magnitude of $\mathrm{NH}_{3}$ emissions generally agreed with other studies conducted on Euro 5/6 vehicles $[15,16]$. The overall level of $\mathrm{N}_{2} \mathrm{O}$ emissions was in line with most reported emissions factors obtained under laboratory conditions (see [10]), although the fact that results from vehicle 1 (WLTC) were so close to the US limit is perhaps somewhat surprising, given the displacement of the engine $\left(<1.5 \mathrm{dm}^{3}\right)$ and the reasonably modest driving energy demand resulting from the vehicle's mass $(<1500 \mathrm{~kg})$. Agreement between the results obtained from the two test vehicles were generally reasonably good, but could be further investigated. In particular, the $\mathrm{NH}_{3}$ emissions occurring over the EUDC phase of the NEDC stood out as showing poor agreement (and were surprisingly high in the case of vehicle 2) a point which could be further investigated. Similarly, further testing of vehicles of this type at higher mileages (e.g. 120,000-160,000 km) is recommended.

Instantaneous concentration traces are available for measurements of this type, for which a continuous stream of exhaust gas is sampled, in contrast to batch analysis (i.e. bag samples - the light-duty legislative test method). Figure 6 shows the RNC concentrations for vehicle 1, tested over the WLTC; $\mathrm{NO}_{2}$ is omitted for the sake of clarity, which is justifiable due to the very low measured concentrations of that species.

The very high values taken by NO at the beginning of the cold start test result from that species, which is generated in-cylinder in large quantities, simply passing through the TWC. Figure 7 shows the same data in the range $0-600 \mathrm{sec}-$ onds and excluding concentrations > $400 \mathrm{ppm}$.

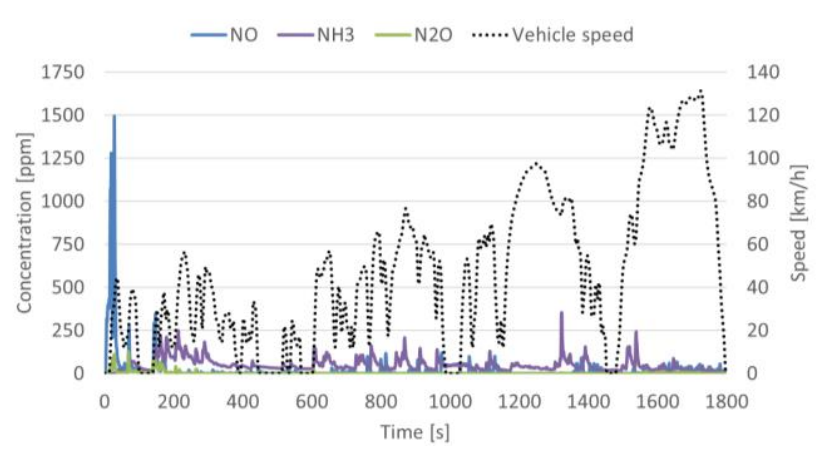

Fig. 6. RNC concentrations from vehicle 1 , tested over the WLTC $\left(\mathrm{NO}_{2}\right.$ not shown)

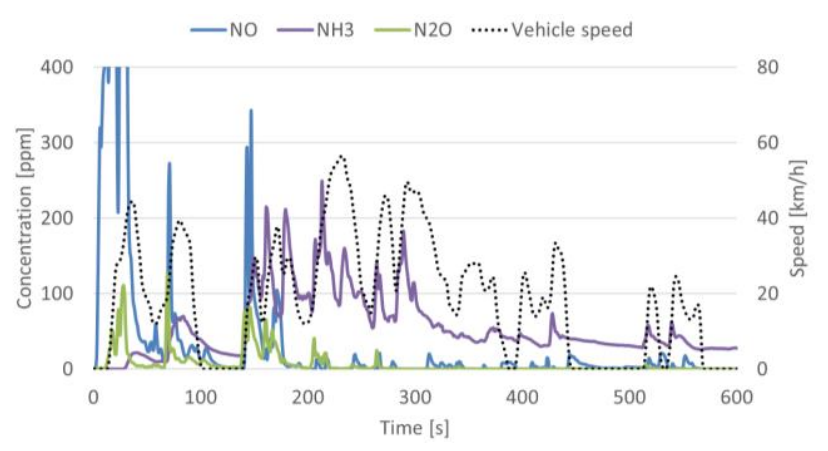

Fig. 7. RNC concentrations from vehicle 1, shown for the first $600 \mathrm{~s}$ of the WLTC $\left(\mathrm{NO}_{2}\right.$ not shown; NO concentrations > 400 ppm not shown $)$

As Figures 6 and 7 show, following the initial surge of $\mathrm{NO}$, values begin to fall as the TWC approaches its light off temperature and begins to convert NO. For this vehicle, during the 0-200 second period of the cycle the $\mathrm{N}_{2} \mathrm{O}$ concentration trace corresponded quite closely to that of $\mathrm{NO}$ (but taking lower values). Production (and release) of $\mathrm{N}_{2} \mathrm{O}$ appeared to start early, at around 15 seconds (during the first acceleration from rest), but took very low values from around 250 seconds onwards. $\mathrm{NH}_{3}$ began to appear at around 30 seconds, but took low values until around 150 seconds, that being the point where $\mathrm{NO}$ and $\mathrm{N}_{2} \mathrm{O}$ values fell sharply. For the entire period $160-600$ seconds, $\mathrm{NH}_{3}$ was the dominant RNC in the exhaust. Following almost 10 minutes' engine operation (approaching 600 seconds), brief surges of $\mathrm{NO}$ and $\mathrm{N}_{2} \mathrm{O}$ continued to occur sporadically, as a result of the dynamics of the speed trace (Fig. 8). As shown in Fig. 8, the quasi-stabilised (almost flat) concentration trace for the period 570-600 seconds (during idling) was at a level of around $28 \mathrm{ppm}$; during that period all other RNCs had concentrations $<1 \mathrm{ppm}$.

As can be seen in Figs 7 and 8, the $\mathrm{NH}_{3}$ (and, to a much lower extent, $\mathrm{N}_{2} \mathrm{O}$ ) concentrations increase during accelerations, an effect reported in virtually every study on $\mathrm{NH}_{3}$ emissions from vehicles of this type. This is largely due to the use of a somewhat richer air-fuel mixture (with lower $\lambda$ values), which is well known to increase the efficiency of the elimination of $\mathrm{NO}_{\mathrm{x}}$ [14]. However, such surges of $\mathrm{NH}_{3}$ emission are limited somewhat by gear changes, which cause a decrease in $\mathrm{NH}_{3} / \mathrm{N}_{2} \mathrm{O}$ and a momentary increase in NO. The behaviour of the turbocharger may also be a relevant parameter here, especially if scavenging is used, which is known to be linked to $\mathrm{NO}_{\mathrm{x}}$ breakthrough in certain cases. Despite this, once $\mathrm{NH}_{3}$ production has started in earnest 
(from around $150 \mathrm{~s}$ in this example - most probably linked to the onset of the water-gas shift reaction, which plays a very important role in $\mathrm{NH}_{3}$ formation [16]), $\mathrm{NH}_{3}$ remains at significant levels during deceleration events and indeed at idle. During fuel cut-off, $\mathrm{NH}_{3}$ production should obviously be very limited (among other reasons, $\mathrm{NH}_{3}$ formation is strongly inhibited by $\mathrm{O}_{2}$ ); yet $\mathrm{NH}_{3}$ concentrations are not observed to fall to zero (or even near-zero) levels (see Fig. 8), unlike for $\mathrm{NO}$ and $\mathrm{N}_{2} \mathrm{O}$, concentrations of which rather rapidly return to near-zero values as the conditions within the TWC no longer favour their emission. The response time of the RNC analyser used conforms to the EU heavy duty type approval requirement (analyser rise time $<5 \mathrm{~s}$ [19]). Assuming that the impact of response time of the analyser is limited, at least some of the observed behaviour may be attributed to outgassing of $\mathrm{NH}_{3}$ from metal surfaces which act as temporary $\mathrm{NH}_{3}$ storage reservoirs and from liquid water which condenses in the exhaust line following a cold start. Ammonia is frequently described as a 'sticky' molecule which readily forms a surface layer of adsorbed molecules on metals such as stainless steel; this is not the case for $\mathrm{NO}, \mathrm{NO}_{2}$, or $\mathrm{N}_{2} \mathrm{O}$. The aforementioned process can accumulate appreciable quantities of adsorbed $\mathrm{NH}_{3}$, but it is emphatically reversable. As the temperature of the exhaust line increases, the favourability of $\mathrm{NH}_{3}$ release from condensed water and metal surfaces increases. After some time, no liquid water will remain in the exhaust line; this effect is determined not only by the temperature of the exhaust gas, but also by the exhaust gas flow rate, with a small influence also exerted by the manner in which the vehicle is cooled in the laboratory (wind speed fan characteristics) and overall powertrain design. Ambient temperature is a further factor of obvious relevance, but was not a variable in this study. The aforementioned processes and resulting effects are by nature chaotic and unpredictable (even for a given vehicle subjected to a given test procedure at a given temperature) and account for a significant proportion of the inherent variability and generally low repeatability of $\mathrm{NH}_{3}$ measurements.

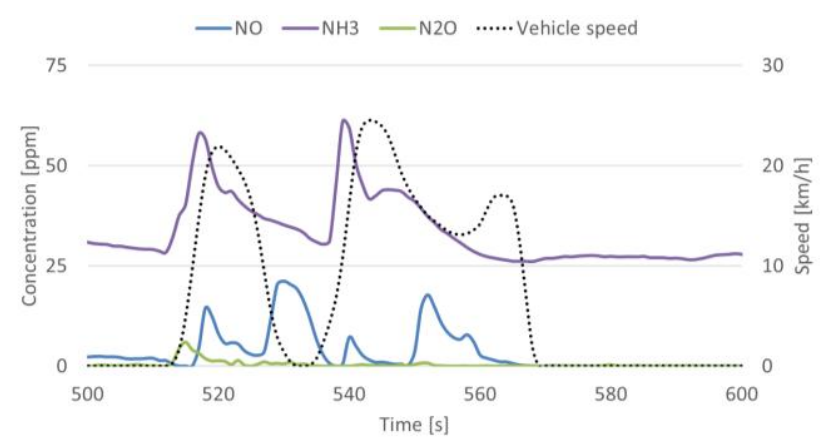

Fig. 8. RNC concentrations from vehicle 1 , shown for the period 500-600 s of the WLTC $\left(\mathrm{NO}_{2}\right.$ excluded for clarity and due to very low concentrations)

The only RNCs subject to legislative limits in the EU are $\mathrm{NO}$ and $\mathrm{NO}_{2}$ (limited together as $\mathrm{NO}_{\mathrm{x}}$, limit for lightduty vehicles with SI engines: $60 \mathrm{mg} / \mathrm{km}$ ). This limit was met it all cases, by a wide margin: emissions from both vehicles were $<50 \%$ of the limit over the WLTC and $<25 \%$ over the NEDC. The contribution of $\mathrm{NO}_{2}$ was nearnegligible (very low in all cases); the fact that $\mathrm{NO}_{2}$ takes low values (sometimes statistically indistinguishable from zero for hot running driving cycle phases) makes the $\mathrm{NO}: \mathrm{NO}_{2}$ ratio highly variable and of limited interest. While the cold start phases of both driving cycles were dominated by emissions of $\mathrm{NO}$ (and therefore $\mathrm{NO}_{\mathrm{x}}$ ) in all cases, over the entire test cycles employed, emissions of $\mathrm{NH}_{3}$ were greater than (or broadly equivalent to) emissions of $\mathrm{NO}$ in three out of the four cases examined - only in the case of vehicle 1 on the WLTC cycle was the RNC profile dominated by $\mathrm{NO}$, with $\mathrm{NH}_{3}$ a distant second. The US $\mathrm{N}_{2} \mathrm{O}$ limit of $6.2 \mathrm{mg} / \mathrm{km}$ was met in all cases, although emissions from vehicle 1 over the WLTC were very close to this level (5.9 $\mathrm{mg} / \mathrm{km})$. The other reference point for $\mathrm{N}_{2} \mathrm{O}$, the Chinese limit $(20 \mathrm{mg} / \mathrm{km})$ was thus obviously met by a wide margin. For $\mathrm{NH}_{3}$, the only direct legislative precedent is the mean concentration-based limit applicable to heavy-duty vehicles. This mean concentration of $10 \mathrm{ppm}$ was exceeded in all tests, by a large margin: the lowest mean $\mathrm{NH}_{3}$ concentration measured during any test was some $35 \mathrm{ppm}$; instantaneous $\mathrm{NH}_{3}$ concentrations took maximum values of several hundred ppm. Despite the very different processes behind emissions of the various RNCs, the cold start phase clearly caused the highest distance-specific emissions. Only in a single case were emissions of any RNC greater over a hot running phase of the driving cycle: $\mathrm{NH}_{3}$ during the EUDC phase of the NEDC, for vehicle 2 .

As the density of $\mathrm{NH}_{3}$ is low in comparison to the density of $\mathrm{NO}\left(76 \%\right.$ difference), a given mass of $\mathrm{NH}_{3}$ contains significantly more molecules than the same mass of NO. Thus, on a molar basis $\mathrm{NH}_{3}$ often dominates the RNC profile, even where gravimetric emissions of NO are substantially higher than $\mathrm{NH}_{3}$. Table 2 shows the proportion of RNCs occurring as $\mathrm{NH}_{3}$ over the entire test cycles, on a molar basis.

Table 2. Molar $\mathrm{NH}_{3}: \mathrm{RNC}$ ratio - proportion of RNCs occurring as $\mathrm{NH}_{3}$, on a molar basis

\begin{tabular}{|l|c|}
\hline Vehicle, test cycle & Molar $\mathrm{NH}_{3} / \mathrm{RNC}_{\text {ratio }}[-]$ \\
\hline 1, WLTC & 0.69 \\
\hline 1, NEDC & 0.86 \\
\hline 2, WLTC & 0.78 \\
\hline 2, NEDC & 0.83 \\
\hline
\end{tabular}

As all the values in Table 2 significantly exceed a value of 0.50 , it can be stated that $\mathrm{NH}_{3}$ dominated the RNC profile on a molar basis, in all four cases. This is also evident from a plot of the real-time value of the $\mathrm{NH}_{3}$ : $\mathrm{RNC}$ proportion during a given test, as shown in Fig. 9. The finding that $\mathrm{NH}_{3}$ emissions could be equivalent to - or even greater than - NO, especially on a non-gravimetric (i.e. molar) basis, has been reported previously [18] and supports the general observation that in the case of vehicles meeting stringent $\mathrm{NO}_{\mathrm{x}}$ emissions limits, $\mathrm{NH}_{3}$ is the dominant $\mathrm{RNC}$ in the exhaust gas during hot running operation (see [17] and references therein).

After around 100 seconds' engine operation following cold start, the parameter begins to take values $>0.5$; it thereafter mostly remains at higher values $(>0.6)$, with some exceptions, where it very briefly falls to values as low as 0.2 . These low values are caused by periods of elevated NO emissions, mainly associated with the sudden transition in engine load caused by gear changes. However, the rela- 
tionship between $\mathrm{NH}_{3}$ : $\mathrm{RNC}$ and vehicle speed and demand for engine power is complex and multi-faceted - consider, for example, the two periods marked with the dotted red line in Figure 9. These periods consist of broadly similar hot running driving conditions, albeit with a higher speed in the case of the second period, yet are characterised by very different behaviour for the value of $\mathrm{NH}_{3}: \mathrm{RNC}$. As higher speed (and thus load) should be associated with somewhat lower $\lambda$ values (and thus increased $\mathrm{NH}_{3}$ production should be expected) this apparent contradiction might be at least somewhat attributable to the temperature [5] and space velocity of the exhaust gas within the TWC.

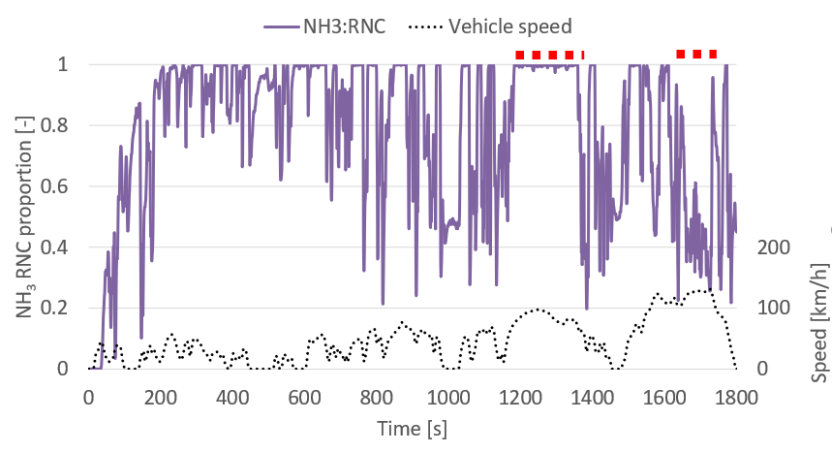

Fig. 9. $\mathrm{NH}_{3}: \mathrm{RNC}$ ratio for vehicle 2, tested over the WLTC. Refer to the text for an explanation of the significance of the dotted red lines

\section{Summary and overall conclusions}

Characterisation of the RNC emissions of two vehicles with downsized, turbocharged SI engines was carried out under laboratory conditions, using two cold start driving cycles with differing characteristics. RNC emissions behaviour was, for the most part, quite similar for the two vehicles and emissions were broadly in line with the findings of other, similar studies. The EU $\mathrm{NO}_{\mathrm{x}}$ limit was easily met; the US $\mathrm{N}_{2} \mathrm{O}$ limit was met in all cases, but the EU $\mathrm{NH}_{3}$ concentration limit (not applicable to this vehicle type) was exceeded in all cases. The RNC profile was dominated by two of the four species: $\mathrm{NO}$ and $\mathrm{NH}_{3}$. Gravimetric $\mathrm{NH}_{3}$ emissions can be at a higher level than gravimetric NO emissions, but are for the most part broadly comparable. However, gravimetric emissions are also a function of the density of the compound, which is relatively low in the case of $\mathrm{NH}_{3}$. On a molar basis, $\mathrm{NH}_{3}$ clearly dominates the RNC profile for the majority of the test, as reflected in the value of $\mathrm{NH}_{3}: \mathrm{RNC}$ - which took values between 0.69 and 0.86 of measured RNCs in the exhaust gas. Cold start urban operation is associated with significant RNC emissions - firstly $\mathrm{NO}$ dominates, then $\mathrm{NO}$ and $\mathrm{N}_{2} \mathrm{O}$ co-exist (but with significantly more of the former), then the commencement of $\mathrm{NH}_{3}$ production causes that species to dominate (overall and generally speaking). This fact has significant implications for urban air quality, especially in light of the short distances often covered in passenger cars, a concern also reviewed in other studies (see [7] for a recent example). Hot running driving is, in most (but not all) cases, associated with lower distance-specific RNC emissions. While the NEDC features an undemanding speed trace leading to lower intrinsic RNC emissions, this is counteracted to a degree by the lower number of kilometres covered, meaning that distancespecific RNC emissions are in some cases comparable to those obtained from the WLTC.

The tendency to form $\mathrm{NH}_{3}$ under a range of driving conditions (including periods of low power demand and even idle) is a disadvantage of certain powertrain designs and TWC configurations. While $\mathrm{NH}_{3}$ (and indeed $\mathrm{N}_{2} \mathrm{O}$ ) remain unregulated in the $\mathrm{EU}$, there is little incentive for manufacturers to optimise emissions control systems (and indeed entire powertrains) to limit their formation and release into the environment. Potential options to limit the formation of $\mathrm{NH}_{3}$ include limiting use of enrichment (i.e. adopting 'flat' $\lambda 1$, or even partially lean combustion $(\lambda>1)$ [12]), as well as the addition of an aftertreatment system component to deal with $\mathrm{NH}_{3}$, concepts for which are shown in Figures 10 and 11.

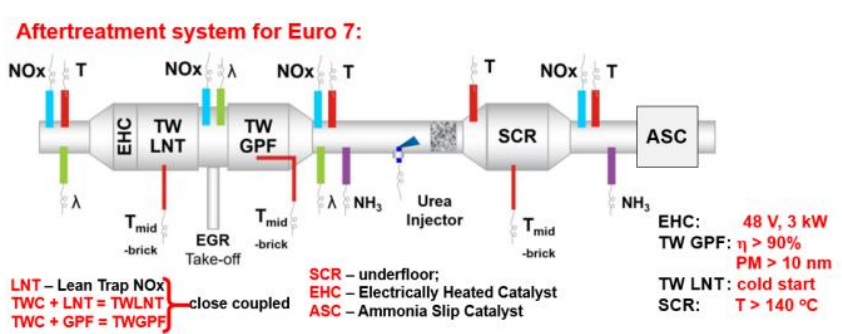

Fig. 10. Aftertreatment system concept to meet future emissions standards (Euro 7), including an ASC for $\mathrm{NH}_{3}$ control [12]

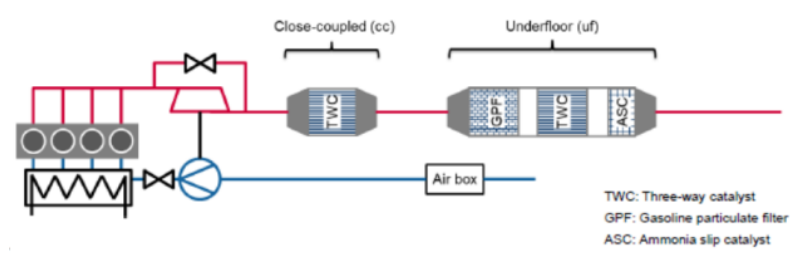

Fig. 11. Aftertreatment system concept to meet future emissions standards (Euro 7), including an ASC for $\mathrm{NH}_{3}$ control [6]

Ammonia slip catalysts (ASC) suitable for use with the exhaust generated by $\lambda 1$ SI engines are undergoing testing and development [6]. Passive SCR systems allowing storage of $\mathrm{NH}_{3}$ for later use in reactions eliminating post-TWC $\mathrm{NO}_{\mathrm{x}}$ have also been mentioned as options for simultaneous $\mathrm{NO}_{\mathrm{x}} / \mathrm{NH}_{3}$ reductions $[9,13]$. It is believed that no equivalent options exist for direct, targeted control of $\mathrm{N}_{2} \mathrm{O}$; the fact that new light duty vehicles sold in the USA must meet a limit of $6.2 \mathrm{mg} / \mathrm{km}$ shows that optimisation of TWCs is able to reduce emissions to below that level. For species associated with cold start and the gradual warmup of the TWC, electrical catalyst heating [8, 12], might prove a solution with many advantages regarding control of RNCs (and pollutants in general [8]).

\section{Nomenclature}

$\lambda \quad$ lambda; the normalised air:fuel ratio

ASC ammonia slip catalyst

$\mathrm{CO}$ carbon monoxide

CC close-coupled 


\begin{tabular}{|c|c|c|c|}
\hline EGR & exhaust gas recirculation & $\mathrm{O}_{2}$ & oxygen (diatomic molecule) \\
\hline $\mathrm{EHC}$ & electrically heated catalyst & OBD & on-board diagnostics \\
\hline EU & European Union & $\mathrm{RNC}$ & reactive nitrogen compounds $\left(\mathrm{NO}, \mathrm{NO}_{2}, \mathrm{NH}_{3}, \mathrm{~N}_{2} \mathrm{O}\right)$ \\
\hline EUDC & extra-urban driving cycle (part of the NEDC) & RON & research octane number \\
\hline GPF & gasoline particulate filter & SCR & selective catalytic reduction \\
\hline $\mathrm{H}_{2}$ & hydrogen (diatomic molecule) & SI & spark ignition \\
\hline $\mathrm{HNCO}$ & isocyanic acid & $\mathrm{T}$ & temperature \\
\hline LNT & lean $\mathrm{NO}_{\mathrm{x}}$ trap & $\mathrm{THC}$ & total hydrocarbons \\
\hline $\mathrm{N}_{2} \mathrm{O}$ & nitrous oxide & TWC & three-way catalyst \\
\hline NEDC & New European Driving Cycle & TWGPF & three-way gasoline particulate filter \\
\hline $\mathrm{N}_{2}$ & nitrogen (diatomic molecule) & TWLNT & three-way lean $\mathrm{NO}_{\mathrm{x}}$ trap \\
\hline $\mathrm{NH}_{3}$ & ammonia & UDC & urban driving cycle (part of the NEDC) \\
\hline $\mathrm{NMHC}$ & non-methane hydrocarbons & UF & under-floor \\
\hline NO & nitrogen monoxide & US(A) & United States (of America) \\
\hline $\mathrm{NO}_{2}$ & nitrogen dioxide & WLTC & Worldwide Harmonised Light Vehicles Test Cycles \\
\hline $\mathrm{NO}_{\mathrm{x}}$ & oxides of nitrogen $\left(\mathrm{NO}+\mathrm{NO}_{2}\right)$ & WLTP & Worldwide Harmonised Light Vehicles Test Procedure \\
\hline
\end{tabular}

\section{Bibliography}

1. BIELACZYC, P., KLIMKIEWICZ, D., WOODBURN, J. et al. Exhaust emission testing methods - BOSMAL's legislative and development emission testing laboratories. Combustion Engines. 2019, 178(3), 88-98.

https://doi.org/10.19206/CE-2019-316

2. BIELACZYC, P., SZCZOTKA, A., PAJDOWSKI, P. et al. Development of automotive emissions testing equipment and test methods in response to legislative, technical and commercial requirements. Combustion Engines. 2013, 152(1).

3. BIELACZYC, P., SZCZOTKA, A., WOODBURN, J. An overview of emissions of reactive nitrogen compounds from modern light duty vehicles featuring SI engines. Combustion Engines. 2014, 159(4), 48-53.

4. BIELACZYC, P., WOODBURN, J., SZCZOTKA, A. Exhaust emissions of gaseous and solid pollutants measured over the NEDC, FTP-75 and WLTC chassis dynamometer driving cycles. SAE Technical Paper 2016-01-1008. 2016.

https://doi.org/10.4271/2016-01-1008

5. BOND, G.C., WEBB, G., HARRISON, B. et al. Catalysis of reactions involving the reduction of decomposition of nitrogen oxides. Catalysis. 1982, 5. https://doi.org/10.1039/9781847553171-00127

6. DEMUYNCK, J. AECC demonstration projects and AECC position on Euro 7. AGVES meeting, 26 November 2020, https://www.aecc.eu/wp-content/uploads/2020/11/201126AECC-presentation-AGVES-1.pdf

7. ELSER, M., EL-HADDAD, I., MAASIKMETS, M. et al. High contributions of vehicular emissions to ammonia in three European cities derived from mobile measurements. Atmospheric Environment. 2018, 175, 210-220. https://doi.org/10.1016/j.atmosenv.2017.11.030

8. FEV Magazine, Zero-Impact - Combustion Engine, 2020. https://magazine.fev.com/en/zero-impact-combustion-engine/

9. GURALP, O., QI, G., LI, W. et al. Experimental study of $\mathrm{NO}_{\mathrm{x}}$ reduction by passive ammonia-SCR for stoichiometric SIDI engines. SAE Technical Paper 2011-01-0307. 2011. https://doi.org/10.4271/2011-01-0307

10. HOEKMAN, S. Review of nitrous oxide $\left(\mathrm{N}_{2} \mathrm{O}\right)$ emissions from motor vehicles. SAE International Journal of Fuels and Lubricants. 2020, 13(1):79-98.

https://doi.org/10.4271/04-13-01-0005
11. MAROTTA, A., PAVlOVIC, J., CIUFFO, B. et al. Gaseous emissions from light-duty vehicles: moving from NEDC to the new WLTP test procedure. Environmental Science \& Technology. 2015, 49(14), 8315-8322, https://doi.org/10.1021/acs.est.5b01364

12. OSBORNE, R., LANE, A., TURNER, N. et al. A newgeneration lean gasoline engine for reduced $\mathrm{CO}_{2}$ in an electrified world. Vienna Motor Symposium 2019, 15-17 May 2019. Vienna, Austria.

13. PRADHAN, S. Development of an ammonia reduction aftertreatment systems for stoichiometric natural gas engines for stoichiometric natural gas engines. Graduate Theses. Dissertations, and Problem Reports. 2017, 6447, https://researchrepository.wvu.edu/etd/6447

14. STRZELEC, A., KASAB, J. Automotive emissions regulations and exhaust aftertreatment systems. SAE International, USA, 2020.

15. SUAREZ-BERTOA, R., ASTORGA, C. Isocyanic acid and ammonia in vehicle emissions, Transportation Research Part D: Transport and Environment. 2016, 49, 259-270. https://doi.org/10.1016/j.trd.2016.08.039

16. SUAREZ-BERTOA, R., MENDOZA-VILLAFUERTE, P., RICCOBONO, F. et al. On-road measurement of $\mathrm{NH}_{3}$ emissions from gasoline and diesel passenger cars during real world driving conditions. Atmospheric Environment. 2017, 166, 488-497. https://doi.org/10.1016/j.atmosenv.2017.07.056

17. SUAREZ-BERTOA, R., ZARDINI, A., ASTORGA, C. Ammonia exhaust emissions from spark ignition vehicles over the New European Driving Cycle. Atmospheric Environment. 2014, 97, 43-53. https://doi.org/10.1016/j.atmosenv.2014.07.050

18. The ICCT. Beyond $\mathrm{NO}_{\mathrm{x}}$ : emissions of unregulated pollutants from a modern gasoline car. 2019. https://theicct.org/sites/default/files/publications/NOx_Polluta nts_LDV_FV_20190503_0.pdf

19. UNECE Regulation No. 49. https://eur-lex.europa.eu/legalcontent/EN/ALL/?uri=CELEX:42013X0624(01) Joseph Woodburn, MSci - Exhaust Emission Labor-
atory, BOSMAL Automotive Research and Deve-
lopment Institute Ltd in Bielsko-Biała, Poland
e-mail: joseph.woodburn@bosmal.com.pl 